\title{
Rupture of unscarred uterus: a multi-year cross-sectional study from Nigerian Christian Hospital, Nigeria
}

\author{
Kelechi N. Eguzo $^{1} *$, Chisara C. Umezurike ${ }^{2}$ \\ ${ }^{1}$ School of Public Health, University of Saskatchewan, Saskatoon, Saskatchewan, Canada \\ ${ }^{2}$ Department of Obstetrics and Gynecology, Nigerian Christian Hospital, Aba, Nigeria
}

Received: 27 October 2013

Accepted: 13 November 2013

\author{
*Correspondence: \\ Dr. Kelechi N. Eguzo, \\ E-mail: keguzo@gmail.com
}

(C) 2013 Eguzo KN et al. This is an open-access article distributed under the terms of the Creative Commons Attribution Non-Commercial License, which permits unrestricted non-commercial use, distribution, and reproduction in any medium, provided the original work is properly cited.

\begin{abstract}
Background: Rupture of the gravid uterus is a known catastrophic event in obstetrics. Rare in developed countries, it contributes to the high maternal mortality in developing countries like Nigeria. Little is known about the determinants of rupture in unscarred uterus, especially in Nigeria, unlike rupture of scarred uterus. This paper studied the factors associated with rupture of unscarred uterus in Nigerian Christian Hospital.

Methods: This was a multi-year, cross-sectional descriptive study of all cases of primary uterine rupture in the hospital between May 2002 and October 2007. Key factors studied include demographics, place of initial presentation in labour, use of uterotonics, duration of labour, maternal and fetal outcome, injury to structures adjacent to the uterus as well as type of surgical intervention.

Results: Rupture of unscarred uterus comprised $40 \%(\mathrm{n}=28)$ of rupture in the study period, with incidence of 8.4 per 1,000 births in the hospital. Most cases aged 25-34 years with parity of 3 or above. A significant proportion of cases were first managed by Traditional Birth Attendants $(\mathrm{p}=0.01, \alpha=0.05)$, and there was statistically significant association between prolonged labour and initial presentation to TBAs $\left(\chi^{2}=16.44, \mathrm{P}<0.001, \alpha=0.05\right)$. Contiguous injuries to the cervix/vagina were most common among the cases. The associated maternal and perinatal mortality rates were $14 \%$ and $93 \%$ respectively.

Conclusion: Primary uterine rupture was found to be associated with high parity and prolonged labour. Initial management by TBAs (with associated prolongation of labour) was strongly correlated to the occurrence of this event. It is recommended that health policy makers emphasize the deployment of competent health workers with obstetrics training in rural areas, to replace the traditional birth attendants.
\end{abstract}

Keywords: Nigeria, Traditional birth attendants, Uterine rupture

\section{INTRODUCTION}

Uterine rupture is a known catastrophic event in obstetrics, often resulting in both maternal and fetal consequences. ${ }^{1-3}$ Uterine rupture is tearing of the uterine wall during pregnancy, delivery, ${ }^{2}$ or after delivery. The incidence of this condition is higher in developing countries, ${ }^{2,3}$ where it is a significant contributor to the high maternal morality.

Many studies have shown a wide array of causes or risk factors for uterine rupture. A Swedish study ${ }^{4}$ showed the risk factors to include previous caesarean, induction of labour, and increasing maternal age. Other factors are height, body mass index (BMI), maternal education, cigarette smoking, birth weight, gestational age, instrumental vaginal delivery, and short inter-pregnancy interval. Of these risk factors, the most important are a uterine scar (mostly from previous caesarean section) and the use of uterotonic agents for induction of labour. ${ }^{5}$

Most cases uterine rupture are known to occur in the background of previous uterine scar, ${ }^{1-5}$ with varying prevalence globally. Okafor and Anibue ${ }^{1}$ showed that 
$60.9 \%$ of the cases in a Nigerian study had unscarred uterus, while Eze and Ibekwe ${ }^{3}$ reported that $62.7 \%$ of their cases had similar features. These reports from Nigeria (a developing country) showed a different trend than is seen in developed countries. A WHO systematic review of uterine rupture showed ${ }^{4}$ that $1.8 \%$ of rupture in South Africa occurred in unscarred uterus. Manoharan et $\mathrm{al}^{6}$ also reported that rupture of an unscarred uterus is a rare event, with the reported incidence between 1 in 12,960 and 1 in 17,000deliveries.

No study, however, has researched into the nature of uterine rupture in unscarred uterus: the etiologic factors and outcome. The essence of this study is to show risk factors that account for high incidence of rupture of unscarred uterus in Nigerian Christian Hospital.

\section{METHODS}

This was a multi-year cross-sectional descriptive study done between May 2002 and October 2007, involving all cases of uterine rupture at Nigerian Christian Hospital $(\mathrm{NCH}) . \mathrm{NCH}$ is a rural, 110-bed secondary-health facility located near Aba, southeastern Nigeria with facilities for emergency obstetric care. The hospital serves as a major referral center for surgery, obstetrics and gynecology in southern Nigeria. Approval for this study was obtained from the Department of Obstetrics and Gynecology, Nigerian Christian Hospital.

Data was collected in a variety of formats, including direct structured interviews with the patients before they were discharged. Information was also collected from patient case notes, maternity ward records and operating room registers in a structured format. The rubric for data collection included: maternal age, parity, booking age (weeks), uterotonics use (oxytocin/misoprostol), previous uterine scar, and presence of uterine contractions at presentation as an indication if the rupture had completed before presentation (no contraction) or if it was ongoing (active contraction) or if there was never contraction before the rupture (not in labor). We also included the vital signs (BP, pulse), presence of active bleeding per vaginam, as well as fetal heart rate at presentation. Hemoperitoneum estimation at surgery was documented as well as the site of rupture.

Also, presence of concomitant injury to adjacent organs (bladder, cervical, vaginal) was noted. The type of surgical intervention was described. Other variables were number of blood units administered, postrupture/operative complications, fetal outcome and maternal outcome (death or live). The location of the products of conception (fetus and placenta) at surgery, content of the uterus at surgery, estimated duration of labor, duration of hospital stay (days) and probable cause of rupture were also studied. Trial of scar status, pre and post-operative hematocrit, fetal birth weight and sex, as well as previous place where the woman was receiving care were all recorded. Data was collated using Microsoft
Excel, but was analyzed using SPSS version 20. P-value $<0.05$ was regarded as statistically significant.

\section{RESULTS}

This study covered a five-year period, 2002-2007. There were 4, 782 deliveries during the study period and 70 cases of ruptured uterus, giving a rupture rate of 14.6 per 1,000 births. $40 \%(n=28)$ of these cases of rupture occurred in unscarred uterus. The incidence of rupture of unscarred uterus in the period was 8.4 per 1,000 live births. The mean maternal age of unscarred uterine rupture cases was 30 years with a range of 22-40 years. Most of the cases of unscarred rupture were aged between 26 and 34 years, and had parity of 3 or above. Further analysis of place of first presentation revealed that $53.6 \%$ of ruptures occurred in TBA homes. This was significantly different from the incidence of rupture in other settings, namely church, home or hospital $(\mathrm{p}=0.01, \alpha=0.05)$. Figure 1 shows the analysis of the place of initial presentation. It is worthy to note that $3(10.7 \%)$ cases of rupture of unscarred uterus occurred in women who were not in labor. Also, comparison with cases of rupture of previously scarred uterus showed that $39.3 \%(n=11)$ of all ruptures in our hospital first presented in the TBA home.

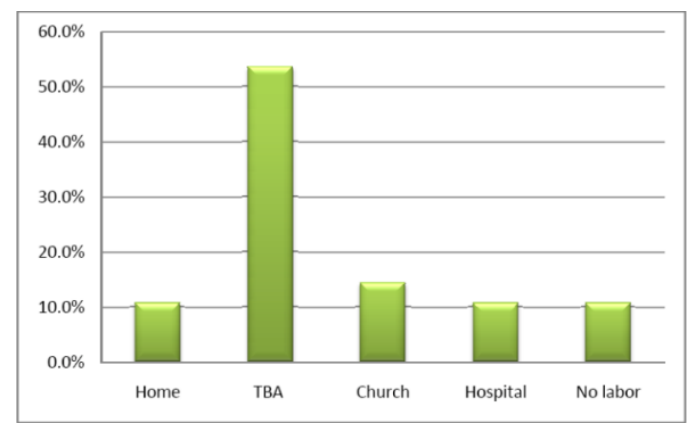

Figure 1: Place of initial presentation.

Analysis of the concomitant injury associated with the rupture of unscarred uterus was conducted. This showed that a higher proportion of injuries $(39.3 \%, n=11)$ involved the cervix/vagina, and this was significantly higher than injuries to other organs $(p=0.01, \alpha=0.05)$. Fifty percent of the cases did not have concomitant injury. However, the data did not show any significant association between place of first presentation and type of associated injury.

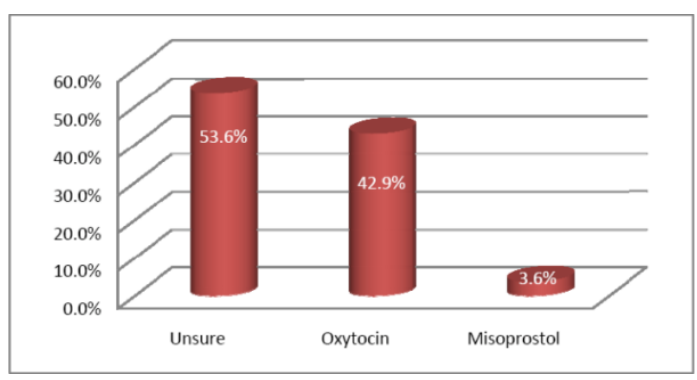

Figure 2: Method of induction. 
Although $42.9 \%$ of the cases of rupture of unscarred uterus reported that they had induction of labor with oxytocin (locally called 'hot drip), this finding was not statistically different from rupture involving the use of misoprostol or absence of induction of labour. Most of the cases $(53.6 \%)$ were not sure if they had any form of induction prior to the rupture (see figure 2). There was no association between the type of induction and the place of initial management or concomitant injury.

The duration of labor for cases of ruptured unscarred uterus was also considered. The mean duration of labor was 25 hours (SD 25.3). This was significantly longer than the duration of normal labor (12 hours) in multipara women $(p=0.001, \alpha=0.05)$. Chi squared analysis showed significant association between prolonged labor $(>12$ hours $)$ and first presentation at a TBA home $(\chi 2=16.44$, $\mathrm{P}<0.001, \alpha=0.05)$. Similarly, we studied the outcome of the rupture. In $50 \%$ of the cases, there was no associated injury to proximal organs (vagina/cervix and adnexia). Injury to the vagina/cervix was most common (see figure 3 ). Death from the rupture or its complications was recorded in $14.3 \%$ of the cases (see figure 4 ), while more than $90 \%$ of the infants died from uterine rupture (figure 5).

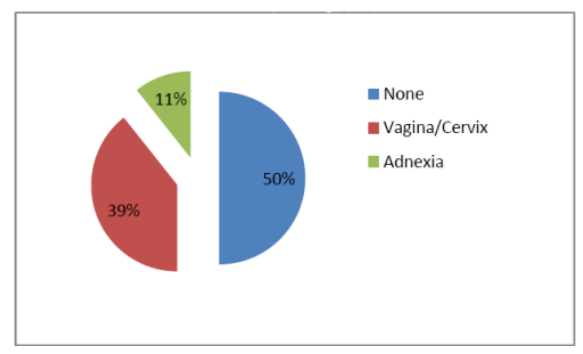

Figure 3: Injury to proximal organs.

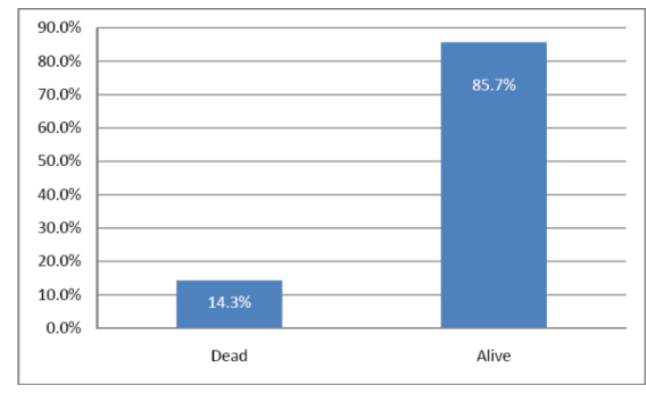

Figure 4: Maternal outcome.

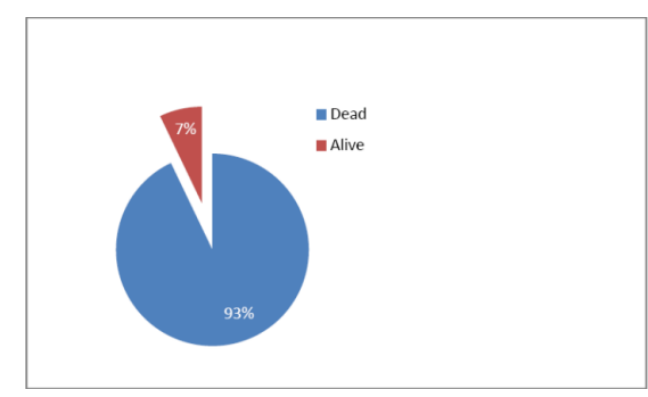

Figure 5: Fetal outcome.

\section{DISCUSSION}

Uterine rupture is a known catastrophic event in obstetrics, often resulting in both maternal and fetal consequences. ${ }^{1-3}$ This event occurs more in developing countries, with a varying global incidence. The incidence of rupture in unscarred uterus in this study was 8.4 per 1,000 live births, and it accounted for $40 \%$ of all cases of uterine rupture at this hospital in the study period. This is significantly lower than the rate $(62.7 \%)$ reported by Eze and Ibekwe ${ }^{3} \quad(p=0.0003$, $\alpha=0.05$ ). This difference further strengthens the findings of the 2008 National Demographic Health Survey, ${ }^{11}$ which showed that more women in Abia State (where our study was conducted) had skilled attendance at labor as well as literacy compared with the setting for the study of Eze and Ibekwe (Ebonyi State). The mean age and modal parity of the patients in this study were similar to those previously reported. ${ }^{3,7}$

In developed countries, rupture of the uterus is largely associated with previous caesarean section. ${ }^{4,5}$ However, in Nigeria this trend is most commonly associated high parity, poor antenatal care, unskilled attendance at labor, rising rate of caesarean section as well as use of uterotonics. ${ }^{3,7}$ Our study similarly identified high parity and non-attendance at antenatal care as important factors. About $89 \%$ of our cases were unbooked and $68 \%$ of them had at least 3 previous deliveries. This study however, showed that the most significant factor in rupture of unscarred uterus was unskilled attendance at labor. Most of the cases were initially managed by the Traditional Birth attendants. Women who first presented at the TBA home were more likely to have prolonged labour $(\chi 2$ $=16.44, \mathrm{P}<0.001, \alpha=0.05$ ).

According to the World Health Organization, ${ }^{8}$ "a traditional birth attendant (TBA) is a person (usually a woman), who assists a woman in childbirth and who acquired her skills by delivering babies by herself or through apprenticeship with other traditional birth attendants". This definition is however slightly different from the practice of TBAs in Nigeria as many of them provide some sort of antenatal and infertility treatment services. ${ }^{9}$ TBAs are known for harmful practices which worsen the maternal mortality in Nigeria., ${ }^{3,9}$ This study has again reiterated the dangers associated with TBAs as they were directly associated with more than $50 \%$ of the cases of rupture in unscarred uterus. Observations at Nigerian Christian Hospital show that TBAs commonly use uterotonics (especially oxytocin) wrongly. They also have a tendency for not referring difficult cases promptly, thus prolonging labour.

Previous studies have suggested interventions to reduce rupture of unscarred uterus. Such suggestions include reduction of unwanted pregnancies; improve accessibility of obstetric services including caesarean section; increase in skilled attendance at labour among other interventions. $^{2,3,7}$ This study suggests that the most 
significant intervention in reducing the incidence of rupture of unscarred uterus has to be focussed on the TBAs. Our opinion is that most of these women (TBAs) are old and deeply entrenched in their negative practices, and may not be amenable to training. This view is strengthen by Cochrane Review of the impact of TBA training. ${ }^{10}$ Evidence shows that although TBA training improved referrals, there was no significant improvement in maternal or perinatal mortality. Thus there is the need to improve skilled attendance at labor by increasing the number of trained health care workers, especially in rural areas such as those served by Nigerian Christian Hospital.

\section{CONCLUSION}

High parity, unbooked pregnancy and use of uterotonics have been shown to be associated with rupture of unscarred uterus in this study. However, unskilled attendance at labor, especially by traditional birth attendants, was a strong factor linked with occurrence of rupture in unscarred uterus. It is highly recommended that health policy makers should intervene by deploying more skilled maternal health workers in rural areas; against the prevalent practice of training (and retraining) of TBAs.

\section{Funding: None}

Conflict of interest: None

Ethical approval: Approved by the Institutional Ethics Committee

\section{REFERENCES}

1. Okafor UV, Aniebue U. Anaesthesia for uterine rupture in a Nigerian teaching hospital: maternal and fetal outcome. International Journal of Obstetric Anesthesia (2006) 15, 124-128.

2. WHO systematic review of maternal mortality and morbidity: the prevalence of uterine rupture, BJOG: an International Journal of Obstetrics and Gynaecology September 2005, Vol. 112, pp. 12211228.
3. Eze JN, Ibekwe PC. Uterine rupture at a secondary hospitalin Afikpo, Southeast Nigeria, Singapore Med J 2010; 51(6):506.

4. Kaczmarczyk M, Spare'n P, Terry P, Cnattingius S. Risk factors for uterine rupture and neonatal consequences of uterine rupture: a population-based study of successive pregnancies in Sweden. BJOG 2007;114:1208-1214.

5. Zwart J, Richters J, O* ry F, de Vries J, Bloemenkamp K, van Roosmalen J. Uterine rupture in the Netherlands: a nationwide population-based cohort study. BJOG 2009;116:1069-1080.

6. Manoharan M, Wuntakal R, Erskine K. Uterine rupture: a revisit The Obstetrician \& Gynaecologist 2010;12:223-230.

7. Ezegwui HU and Nwogu-Ikojo EE. Trends in uterine rupture in Enugu, Nigeria. Journal of Obstetrics and Gynaecology, April 2005; 25(3): 260-262.

8. World Health Organization. Traditional birth attendants: a joint WHO/UNICEF/UNFPA statement. Geneva: World Health Organization, 1992.

9. Ofili AN and Okojie OH. Assessment of the role of traditional birth attendants in maternal health care in Oredo Local Government Area, Edo State, Nigeria. Journal of Community Medicine and Primary Health Care. June 2005;17(1):55-60.

10. Sibley LM, Sipe TA, Brown CM, Diallo MM, McNatt K, Habarta N. Traditional birth attendant training for improving health behaviours and pregnancy outcomes. Cochrane Database of Systematic Reviews 2007, Issue 3. Art. No.:CD005460. DOI: 10.1002/14651858.CD005460.pub2.

11. National Population Commission (NPC) [Nigeria] and ICF Macro. Nigeria Demographic and Health Survey2008. Abuja, 2009 http://www.measuredhs. com/pubs/pdf/OF12/OF12.SE.5.english.pdf.

DOI: $10.5455 / 2320-1770 . i j r \operatorname{cog} 20131232$

Cite this article as: Eguzo KN, Umezurike CC. Rupture of unscarred uterus: a multi-year crosssectional study from Nigerian Christian Hospital, Nigeria. Int J Reprod Contracept Obstet Gynecol 2013;2:657-60. 